\title{
Lazer e esporte: olhar dos professores de disciplinas esportivas do curso de educação física
}

CDD. 20.ed. 378.013

790.1

796.5

\author{
Renata RAMOS* \\ Hélder Ferreira ISAYAMA*
}

\section{Resumo}

0 objetivo deste estudo foi diagnosticar e analisar a inserção dos conhecimentos sobre o lazer nos conteúdos desenvolvidos nas disciplinas esportivas do currículo do curso de formação superior em Educação Física da Universidade Federal de Minas Gerais (UFMG), a partir do olhar de professores dessas disciplinas. Em relação à metodologia, o estudo se caracterizou pela combinação da pesquisa bibliográfica e de campo. Na pesquisa bibliográfica, foi realizada uma revisão de literatura, através da leitura de livros, artigos científicos, monografias, dissertações e teses sobre Educação Física, Esporte, Lazer e Formação Profissional. Para a pesquisa de campo, utilizamos a técnica de entrevista semi-estruturada para a coleta dos dados, junto a oito professores do curso analisado, selecionados por lecionarem, no segundo semestre de 2007, disciplinas que abordam modalidades esportivas. Os dados coletados foram analisados qualitativamente através da técnica de análise de conteúdo. Foi identificado que a maioria dos professores, cerca de 60\%, afirmou que aborda o lazer nas disciplinas que leciona, enquanto cerca de $40 \%$ afirmou que não o aborda. Os professores destacam a presença do lazer nas disciplinas esportivas de diferentes maneiras, alguns apontam o lazer como uma das possibilidades de manifestação do conteúdo esportivo, outros associam o lazer a ideia de jogos e brincadeiras que podem ser realizados no decorrer dos cursos. Além disso, o lazer para os sujeitos é visualizado como espaço de compensação do trabalho, como meio para produzir atletas, bem como espaço de vivências lúdicas voltado principalmente para o público infantil, dentre outros entendimentos observados.

UnITERMOS: Lazer; Esporte; Formação profissional.

\section{Introdução}

O esporte é uma manifestação cultural de grande importância nos dias de hoje e está presente em diversos espaços de atividades humanas, como clubes, federaçōes, confederaçōes, escolas, academias, empresas, igrejas, asilos, prisões, organizado formal ou informalmente. Segundo Vargas (1995), o esporte vem sendo a grande matriz de espetáculos dos dois últimos séculos. Essa manifestação cultural tem espaço em diversos programas de televisão, jornais, revistas, rádios, filmes, internet e outros meios de comunicação. A mídia cobre não somente os jogos, mas também os treinos, preparativos, decisōes dos grandes clubes e até a vida pessoal de atletas famosos.

Na perspectiva econômica, hoje o esporte é apontado como um dos maiores produtos de negócios e assistimos uma crescente profissionalização de sua administração, sendo capaz de mexer com sonhos e difundir ideias, comportamentos, atitudes (Melo, 2004). O esporte enquanto negócio cria novas possibilidades de bens e serviços representados pelas indústrias de materiais, fonte de arrecadação de recursos financeiros para investimentos sócioeconômicos, meio de marketing das empresas e por permitir a exportação de atletas e técnicos "talentosos" (Guimarães, 1996).

De acordo com STIGGER (2002), várias razões podem ser atribuídas à dificuldade de definir ou encontrar a essência do esporte. Uma delas é o grande número de atividades já existentes no âmbito da cultura corporal, às quais se tenta atribuir o "status" de esporte, à medida que passam a ser praticadas com regras padronizadas, regulamentos rígidos e vinculadas às federaçôes. Outra 
razão é a capacidade de ressignificação do esporte por parte de seus praticantes, os quais o realizam no tempo livre, e o adaptam a aspectos de sua realidade particular, vinculado aos seus interesses, valores, possibilidades e motivações.

Com relação à apropriação do esporte pelos sujeitos surgem na literatura alguns conceitos que traduzem as diferentes possibilidades de apropriação da prática esportiva. BRACHT (1989) e BETTI (1993) fazem uso de um esquema dual para classificar o esporte, pois acreditam que, de maneira geral, este se caracteriza como de alto rendimento ou espetáculo, ou enquanto atividade de lazer. Já o esporte-escolar pode se vincular a uma dessas tendências. Entretanto, BRACHT (1989) afirma que essa conceituação do esporte é limitada, pois não esclarece as interelações existentes entre o esporte de lazer e o esporte espetáculo, como, por exemplo, o fato do último, em linhas gerais, fornecer o modelo para a prática do primeiro. Dentro disso, ele destaca que a diferenciação destas duas manifestações em direção a uma possível autonomia encontra sérias dificuldades, visto que as organizações esportivas e empresas que dominam o esporte espetáculo buscam incorporar as formas alternativas de prática esportiva que surgem para não perder o poder de determinar as formas legítimas de sua prática.

O esporte de alto rendimento ou espetáculo apresenta hoje como característica central a transformação do mesmo em mercadoria veiculada pelos meios de comunicação de massa, e tende a assumir as características dos empreendimentos com fins lucrativos, com proprietários e vendedores da força de trabalho submetidos às leis do mercado. O sentido interno das açôes no interior desta instituição é pautado pelos códigos da vitória-derrota, da maximização do rendimento e da racionalização (BRACHT, 1989).

Com relação ao esporte de lazer, o autor afirma que este pode ser vivenciado pelas pessoas através de sua prática ou assistência do esporte espetáculo ou da própria experiência do esporte como lazer. Ele não é uma manifestação homogênea, mas apresenta formas que são imediatamente derivadas do esporte de rendimento ou espetáculo e que a ele se assemelham, como outras que dele divergem quanto a aspectos meramente formais, mas também quanto ao sentido interno das ações (BRACHT, 1989). Isso ocorre porque mesmo que o esporte constitua um elemento da cultura que traz consigo muitas características que lhe são específicas, quando apropriado pelos atores sociais nas suas práticas localizadas e particulares, estes têm a liberdade de produzir novas formas de vivenciá-lo, o que resulta em manifestações bastante diversificadas (STIGGER, 2002).
Tanto o esporte de lazer, quanto de rendimento ou espetáculo, com suas semelhanças e diferenças, possuem grande importância por serem formas de expressão do esporte, que é um patrimônio histórico-cultural da humanidade. Além disso, o esporte tem influenciado a história de diferentes nações e das relações entre elas, e, de maneira mais pontual, proporcionado experiências ricas para as pessoas que o apropriam de diferentes maneiras.

Entretanto, muitas vezes o esporte tem sido mais valorizado pelo seu potencial economicamente lucrativo, como produto de marketing de empresas e como forma de enaltecer o Estado. Estes aspectos têm levado a uma supervalorização do esporte de rendimento em detrimento de suas outras formas de manifestação. Além disso, existe uma "visão funcionalista" do esporte de lazer, que não o valoriza em si mesmo, mas como um meio de recuperar as energias para o trabalho e promover atletas para o esporte de rendimento.

No que se refere à política pública, o esporte apresenta uma trajetória de politização no Brasil, já que a instituição esportiva apresenta-se como "lócus" onde coexistem interesses variados e potencialmente antagônicos (LinHALES, 1996). Segunda a autora, seu percurso é marcado pelo conflito protagonizado por diferentes atores sociais, dentre eles o estado, sendo reconhecido como direito social pela Constituição Federal de 1988. No entanto, o desafio atual do Estado é realizar políticas que possibilitem a efetivação desse direito para todos, não de forma protecionista e tutelar, como aconteceu em alguns momentos, mas flexível e democrática.

É interessante observar que, apesar do reconhecimento do esporte enquanto direito social e dever do Estado, considerado como um avanço político, a Constituição não esclarece os procedimentos que o Estado utilizará para fomentar as práticas esportivas, nem como incentivará as manifestações esportivas. Além disso, o artigo afirma que os recursos públicos serão destinados prioritariamente para o esporte educacional e, em casos específicos, para o esporte de alto rendimento. Então, surge um questionamento: como será garantido o direito ao esporte daqueles que não o praticam em nenhum desses dois espaços?

Outra questão a ser problematizada pelo Estado é o incentivo ao lazer como forma de promoção social. E nesse caso, ocorre uma valorização do esporte de lazer como um meio de promoção e descoberta de "talentos esportivos" para o esporte de rendimento, já que se tornar atleta era entendido como uma forma de promoção social. 
De qualquer maneira, o conhecimento destes aspectos sobre as diferentes dimensões do esporte deveria levar profissionais de Educação Física, bem como aqueles que participam dos processos de formação de profissionais nesse campo, a refletirem sobre como podem contribuir para que as diferentes formas de expressão do esporte sejam valorizadas, buscando a efetivação do direito e o acesso ao esporte para todos. E dessa forma, esses profissionais poderiam contribuir para que o esporte venha ser tratado como um direito social, buscando trabalhar na educação dos diferentes atores sociais para concretizar a efetivação desse direito.

É nesse contexto que surgem algumas indagaçōes que motivaram a realização desse estudo: haveria alguma relação entre os conteúdos da formação profissional em Educação Física e a priorização do rendimento nas aulas de esportes? Qual a compreensão sobre esporte e sobre lazer dos professores ligados a cursos de graduação em educação Física? Será que os professores das disciplinas esportivas do curso de Educação Física abordam o esporte enquanto um conteúdo cultural que pode ser vivenciado no lazer? De que forma?

\section{Metodologia}

Como metodologia de trabalho, combinamos as pesquisas bibliográfica e de campo. Primeiramente, realizamos uma revisão de literatura, através da leitura e análise de livros, artigos científicos, monografias, dissertações e teses sobre os temas: Educação Física, esporte, lazer, formação profissional.

Em seguida, solicitamos ao Colegiado do curso de graduação em Educação Física a relação das disciplinas que foram ofertadas no segundo de 2007. Para delimitação da amostra, buscamos uma característica em comum dentre as disciplinas, já que várias abordam o conteúdo esporte, direta ou indiretamente, a partir de diferentes campos de conhecimento. O critério para a seleção foi a presença de um esporte específico como conteúdo central do curso, assim escolhemos disciplinas que tinham o nome de uma modalidade esportiva no título. Assim, as disciplinas selecionadas foram: Ensino de Futebol, Ensino de Ginástica Olímpica, Ensino de Voleibol, Futebol I, Futsal, Ginástica Olímpica II, Handebol II, Judô I e Tênis, as quais intitulamos de "disciplinas esportivas" para efeito deste estudo.

Em seguida, solicitamos novamente ao Colegiado do curso a relação dos professores que lecionavam as disciplinas selecionadas para o estudo. De posse
É importante destacar que o olhar dos professores dessas disciplinas sobre o esporte e sobre o lazer possui uma grande influência na condução das mesmas, pois eles participam na construção das ementas, são responsáveis pelo planejamento das aulas, pela seleção da bibliografia que será utilizada e ministram as aulas, de modo geral, com certa autonomia. Além disso, GARCIA (1997) afirma que a palavra do educador tem uma grande influência sobre os alunos, e estes tendem a tomar como ponto de referência a opinião de seus professores.

Diante dessas questôes, o objetivo deste estudo é diagnosticar e analisar a inserção dos conhecimentos sobre o lazer nos conteúdos desenvolvidos nas disciplinas esportivas do currículo do curso de formação superior em Educação Física da UFMG, a partir do olhar de professores. Dentre os seis cursos superiores de Educação Física presentes na cidade de Belo Horizonte, a opção pelo curso da UFMG foi devido a este ser o mais antigo da cidade, bem como pela acessibilidade dos pesquisadores a essa instituição.

dessas informações, entregamos uma carta para cada um desses professores, contendo a descrição da pesquisa e um pedido de agendamento de uma entrevista semi-estruturada.

A opção da análise da inserção dos conteúdos sobre o lazer nas disciplinas esportivas ter sido a partir do olhar dos professores é em função da importância dessas visōes para o desenvolvimento das disciplinas. Os professores conduzem as disciplinas como um todo: participam na construção das ementas, são responsáveis pelo planejamento das aulas, pela seleção da bibliografia que será utilizada e ministram as aulas, de modo geral, com autonomia. Assim, as experiências deles, bem como a visão que apresentam sobre o esporte e o lazer, são determinantes na forma como abordam esses conteúdos nas disciplinas que lecionam.

A entrevista semi-estruturada foi à técnica de coleta de informaçôes por valorizar a presença do investigador, ao mesmo tempo em que oferece todas as perspectivas possíveis para que o informante alcance a liberdade e a espontaneidade necessárias, enriquecendo a investigação. Esta técnica parte de certos questionamentos básicos, apoiados em teorias e hipóteses, que interessam à pesquisa, e que, em seguida, 
oferecem amplo campo de interrogativas, fruto de novas hipóteses que vão surgindo à medida que se recebem as respostas do informante (TRIVINÓs, 1992).

Todos os professores das disciplinas selecionadas, total de oito sujeitos, se disponibilizaram para a entrevista e assinaram um termo de consentimento livre e esclarecido antes de sua realização, concordando em participar voluntariamente da pesquisa.
Os dados coletados foram analisados qualitativamente através da técnica de análise de conteúdo, que se constitui em um conjunto de técnicas que privilegia a descrição do conteúdo das mensagens, permitindo a obtenção de indicadores qualitativos e quantitativos, que possibilitam a inferência de conhecimentos relativos às condições de produção de tais mensagens (TRIVINŌs, 1992).

\section{Os olhares dos professores: resultados e discussão}

\section{Formação e atuação: professores em foco}

Em relação à formação profissional dos professores que constituíram a amostra deste estudo, todos possuem curso superior e mestrado na área de Educação Física, sendo que os cinco sujeitos graduaram-se na própria UFMG, e dois também fizeram mestrado na Instituição. Dois deles estão realizando o doutorado, enquanto os outros, com exceção de um, já o fizeram, além disso, dois participantes também possuem pós-doutorado.

Vários professores realizaram parte da sua formação acadêmica em outros países, como na Alemanha, Argentina, Austrália, Canadá, Colômbia, Estados Unidos e Portugal. Este é um aspecto importante, tendo em vista as diferenças culturais, resultando em concepçôes diversas sobre Educação Física, Esporte e Lazer, bem como sobre a relação entre essas áreas. Esse aspecto influência na visão dos professores sobre as mesmas, conforme explicitado no trecho a seguir:

$\mathrm{Na}$ Alemanha, nós temos um conceito diferente de esporte daqui, que é um país latino. Aqui, no Brasil, se relaciona muito esporte com esporte de rendimento, né? Mas como eu falei, para nós, existe, a gente fala "recreation sport", esporte recreativo. Eu posso jogar tênis a nível competitivo ou recreativo, eu posso jogar futebol a nível competitivo ou recreativo, ou capoeira [...] (Entrevistado 2).

Outra questão de influência na visão de lazer dos professores é a época em que concluíram seus cursos de Educação Física. Quatro sujeitos se formaram na década de 70, enquanto os outros, na década de 80, apenas um deles se formou após 1987. É importante destacar esse período, pois, conforme demonstra IsAYAMA (2003) foi a partir da Resolução 03/87, do Conselho Federal de Educação, sobre os currículos de cursos de graduação em Educação Física que muitas das disciplinas que tratavam apenas da recreação passaram a associá-la com o lazer. Esse aspecto foi visualizado pelo autor nas denominações das disciplinas, ementas e programas de curso, de forma geral.

Assim, na época em que a maioria dos professores dessa amostra se graduou, ainda não havia uma discussão nos cursos de Educação Física sobre os estudos críticos do lazer, na maioria das vezes discutia-se apenas recreação em uma perspectiva técnica e "prática". Assim, esses professores investiram em estudos nas outras áreas de conhecimento e é possível que não tenham acessado as discussões que vem sendo efetuadas sobre lazer, principalmente a partir da década de 80 , e com isso continuam atrelando lazer a ideia de recreação.

Esta associação entre lazer e recreação é muito comum em nossa trajetória. Entretanto, estes termos apresentam idéias diferentes: a recreação está relacionada com a realização de atividades educativas que ocorrem, muitas vezes, de forma não sistematizada. Já o lazer, de acordo com WERNECK (2004a), é considerado: uma dimensão da cultura que compreende a vivência lúdica de manifestaçōes culturais em um tempo/espaço conquistado pelo sujeito ou grupo social, estabelecendo relaçôes dialéticas com as necessidades, os deveres e as obrigaçōes, especialmente com o trabalho produtivo (p.184).

No que diz respeito à atuação dos professores no Ensino Superior, cinco entrevistados atuam há um período entre 12 e 15 anos; um atua há 20 anos e dois entre 25 e 30 anos. Todos os professores já lecionaram outras disciplinas, além daquelas pelas quais foram selecionados para esta pesquisa, principalmente relacionadas aos campos de estágio e ao treinamento esportivo.

Em relação às experiências pessoais dos professores com o esporte, todos mencionaram terem sido atletas, com exceção de um dos participante da pesquisa. Esta foi uma experiência de grande influência não só na vida pessoal deles, mas também profissional, já que vieram a trabalhar com esportes, como ressalta o sujeito 4 : 
Bom, no âmbito pessoal eu fui atleta desde oito anos de idade. Quer dizer, comecei com oito, com 10 é que comecei a competir. Bom, então eu acho que minha formação foi ali. Então, eu acho que o que eu sou formada hoje eu devo a ginástica. Não só aos meus treinadores, que me ensinaram a formar como pessoa, porque com 12 anos eu fazia parte da seleção brasileira e passei três meses na Alemanha. Então, quer dizer, é uma fase muito inicial pra você estar formando. Então, pra mim, a minha formação foi a Ginástica.

Quatro entrevistados também relataram, ao longo da entrevista, experiências com o esporte no âmbito do lazer, no entanto, outros três mencionaram algumas vivências que parecem relacionar-se com o lazer, entretanto, não deixaram claro que as consideram como experiências dessa natureza.

No que se refere às experiências profissionais com o esporte, todos os professores, com exceção de um, trabalharam em equipes de esporte de rendimento, seja como técnicos, fisiologistas, no campo da psicologia do esporte, bem com na formação de treinadores para equipes de rendimento. Quatro sujeitos também foram professores de Educação Física escolar, e dois deles mencionaram ter trabalhado com o esporte em espaços de lazer.

Esses dados revelam que, de modo geral, os professores dessa amostra tiveram mais experiências profissionais com o esporte relacionado ao treinamento esportivo do que ao lazer e à Educação Física escolar. Assim, é provável que eles tenham maior habilidade e facilidade em compartilhar conhecimentos sobre a atuação profissional naqueles espaços.

\section{Concepções e significados de lazer}

Em relação ao entendimento de lazer dos professores, a maioria (seis sujeitos) relacionou o lazer com atividades ou experiências que geram prazer. Alguns (três sujeitos) também o relacionaram com tempo livre ou com atividades vivenciadas no tempo livre. Podemos observar esses aspectos na seguinte afirmação do sujeito 3:

Lazer, pra mim, são atividades que não são obrigatórias, que eu posso fazer por minha livre escolha. Lazer, pra mim, é o que eu posso utilizar no meu tempo livre, pra fazer atividades diversas, que eu posso, que me dêem prazer.

O sujeito 4 também relacionou o lazer com atividades que trazem um retorno emocionalmente favorável para a pessoa estar feliz:
Bom, lazer é um tempo livre, eu entendo um pouco isso, é aquele tempo livre, é aquele tempo que você vai fazer alguma atividade prazerosa, livre, e que te dê um retorno emocionalmente favorável para você ser alegre, ser feliz, estar de bem com essas atividades, e fazer uma coisa que você gosta, principalmente, um pouco isso.

Já o sujeito 1 relacionou o lazer com o bem-estar das pessoas:

Eu acho que o lazer é aquele momento que você pensa em você exclusivamente. Você pode até estar compartilhando esse momento com outras pessoas, mas aquele momento é único, ele é seu. Você está pensando no seu bem estar, na minha concepção o lazer é isso, o meu bem estar.

De fato, os parâmetros destacados pelos entrevistados tem uma relação direta com o entendimento de lazer apresentado por diferentes autores, tais como: a vivência no tempo livre ou no tempo disponível, bem como a busca por satisfação ou prazer, de acordo com MARCELLINo (1987). Esses parâmetros vem sendo destacados pelos autores desde a década de 70, quando surgiram os primeiros estudos que repensaram a compreensão do lazer simplesmente como tempo liberado do trabalho. Dumazedier (1979), sociólogo francês cuja produção teórica sobre o lazer gerou grande repercussão, até os dias de hoje, elaborou um sistema de caracteres específicos e constituintes do lazer, como o caráter liberatório - é liberado de obrigaçóes institucionais e resulta de uma livre escolha - e hedonístico - é marcado pela busca de satisfação, prazer, alegria e bem-estar.

No entanto, outros entrevistados o lazer, como o sujeito 7 acredita que o lazer também pode estar presente no trabalho:

Entendo, hoje, que o lazer representa uma oportunidade do indivíduo vivenciar uma, vamos dizer assim, uma oportunidade de experiências prazerosas, certo? E aí, isso cabe em vários níveis, em várias situaçôes, cabe desde dentro de um local de trabalho até fora de um local de trabalho.

Já o sujeito 5 afirma não ter clareza da relação entre lazer e "ganhar dinheiro". Segundo ele, algumas pessoas do meio científico defendem a ideia de que se uma atividade gera lucro, ela não pode ser considerada de lazer. Ele discorda dessa ideia, pois acredita que se a atividade lucrativa gerar prazer, ela pode ser considerada de lazer, desde que não haja uma grande cobrança, como ocorre com os atletas em relação à performance.

De acordo com Marcelino (1987), Melo e Alves Junior (2003) e Werneck (2004a) o lazer 
tem uma relação direta com a dimensão do prazer, o que não possibilita entender o trabalho como lazer. Por isso, é preciso refletir que o prazer não deveria ser compreendido como exclusividade do lazer, já que as pessoas podem (e devem buscar) ter prazer no trabalho e em diversas dimensões de suas vidas, o que não caracteriza, por conseguinte, essas dimensões como lazer.

Essa separação entre trabalho e lazer é muito tênue, por isso não podemos estabelecer categorias rígidas já que estamos falando de dimensôes da cultura, que deve ser entendida de maneira ampla. A tendência é considerar que as duas esferas são diferentes, mas que estabelecem relações dialéticas. No entanto, essa discussão apresenta aspectos divergentes de acordo com a perspectiva trabalhada. E isso é demonstrado inclusive no nosso Universo de pesquisa, pois enquanto os sujeitos 5 e 7 incluíram a dimensão do trabalho no entendimento de lazer, o sujeito 8 foi enfático ao separar esses campos:

O lazer faz parte da cultura e é exatamente tudo aquilo que se opõe ao trabalho, não há dúvidas.

Digamos assim, a vida social se divide nesses dois momentos: o momento do trabalho e o momento do lazer.

Uma questão importante é que, na vida cotidiana, nem sempre existem fronteiras absolutas entre o trabalho e o lazer, tampouco entre o lazer e as obrigações sociais, religiosas e política. Afinal, não vivemos em uma sociedade composta por dimensóes neutras e desconectadas umas das outras (WERNECK, 2004a). Por exemplo: uma pessoa que trabalha diante de um computador pode acessar o seu e-mail ou outros sites durante o trabalho, mas com fins ligados ao lazer. Portanto, o lazer é uma dimensão da vida que se relaciona com as outras dimensões e, ao estudarmos este campo de conhecimento, devemos levar em conta essa sua complexidade.

Outro entendimento de lazer apontado por alguns professores foi de que ele é um espaço de compensação do trabalho:

Acho que o lazer tem para mim um significado muito grande de compensação de trabalho e do estresse. Como nossa vida é muito agitada, muito estressada, a gente precisa, digamos, eu falo, tempo de compensar. Por esse motivo, atividades de lazer são importantes. O lazer é extremamente importante para uma sociedade que tem tanta pressão e competição (Sujeito 2).

Esta compreensão de lazer o coloca em uma posição de menor importância em relação ao trabalho, bem como sem valor em si mesmo, já que se torna um espaço compensatório ou para recuperar as energias para o trabalho. Com o avanço da industrialização, o Estado Brasileiro difundiu uma visão chamada de funcionalista do esporte de lazer, bem como do lazer, em geral. As reflexōes iniciais sobre o esporte como um direito social, partiram da ideia de que o Estado deveria colocá-lo ao alcance de todos, como um fator de compensação e equilíbrio às múltiplas exigências impostas pela modernidade. Assim, este foi um dos discursos assimilados pela sociedade para justificar o lazer, em meio a um sistema que supervaloriza a produção e o rendimento.

Um aspecto interessante sobre o entendimento de lazer dos professores que destacamos, é que eles demonstraram não restringi-lo à prática de esportes e atividades físicas. Como afirma o sujeito 2:

Seria importante ensinar a nossos alunos também que lazer não é só praticar esporte, que lazer tem o lado cultural, por exemplo, ler um bom livro, ir ao cinema ver um bom filme, ir ao teatro. Eu tenho um conceito bem amplo de lazer.

Essa afirmação demonstra um entendimento de que o lazer abrange diversas manifestaçōes culturais e, por isso, diversas áreas de conhecimento, o que está de acordo com vários estudos e açōes desenvolvidos no campo.

No entanto, problematizamos a questão apontada pelo professor de que o lazer "não é só praticar esporte, que tem o lado cultural". De acordo com Melo e Alves Junior (2003), em linhas gerais, cultura é o conjunto de valores, normas e hábitos que regem a vida humana em sociedade. Assim, ao falar de cultura, estamos nos referindo a algo amplo e complexo, que abarca linguagens, ritos, símbolos, relações sociais, disputas de poder, enfim, nos referimos a um campo de tensóes e conflitos. Além disso, não existe uma cultura, mas "culturas". Assim, devemos ter o cuidado de não restringir o termo cultura a certas manifestaçôes, como vem acontecendo quando cultura é associada ao campo das artes plásticas, do cinema, da música e da literatura. $\mathrm{O}$ esporte também é uma manifestação que faz parte de várias culturas no mundo e ao ser apropriado por diferentes contextos culturais, pode apresentar diferentes estruturações e sentidos.

\section{Esporte e lazer: considerações}

No que se refere à relação do esporte com o lazer, todos os professores afirmam que existe uma relação entre esses campos, por diferentes razões. A maioria afirma que essa relação é devido à possibilidade de 
vivenciar o esporte como atividade de lazer. Esses professores diferenciaram o esporte de lazer do esporte de rendimento, e alguns (quatro sujeitos) apresentam visōes sobre as diferentes formas de manifestação do esporte:

O esporte tem diferentes formas de manifestação e, dentro dessas diferentes formas de manifestação, existem níveis de exigências de rendimento, e existe o esporte de lazer [...]. Uma das formas de manifestação do esporte é o lazer, existe esporte de lazer, existe esporte de rendimento, existe esporte escolar, existe esporte na escola, são formas diferentes de manifestação do esporte, existe esporte profissional (Sujeito 8).

$\mathrm{Na}$ busca de traduzir em conceitos as diferentes possibilidades de prática esportiva, surgem inúmeras classificações do esporte. A Constituição Federal de 1988, por exemplo, diferencia o esporte em três manifestaçōes: desporto - performance, desporto participação e desporto - educação, o que está de acordo com a afirmação do sujeito 8. Entretanto, devemos nos lembrar de dois aspectos: o primeiro é que dentro de cada um desses tipos de manifestação do esporte também existem diferenças e particularidades, de acordo com o contexto cultural e grupo social que o pratica. $\mathrm{O}$ segundo se refere às interelações das diferentes manifestações esportivas, como o fato de que, em geral, o esporte espetáculo fornece o modelo de prática para o esporte de lazer.

O esporte de lazer também influencia o esporte de rendimento. $\mathrm{O}$ vôlei de praia, por exemplo, surgiu a partir de pessoas que se apropriaram do vôlei de quadra em um contexto diferente, com um número de praticantes diferente, e tornou-se uma modalidade esportiva, praticada também no alto rendimento (Vlastuin \& Pilatti, 2005).

Ao contrário da maioria dos professores dessa amostra, os quais diferenciaram o esporte de rendimento do esporte de lazer, o sujeito 4 afirmou que a prática do esporte de rendimento pode ser uma vivência de lazer: eu acho que necessariamente se você faz, mesmo no meu lado competitivo, se eu estou lá fazendo a Ginástica é porque eu quis fazer, porque eu escolhi fazer e porque me deu prazer de fazer [...]. Então, eu acho que tem essa grande relação, porque você faz porque você escolhe, porque você gosta e porque você tem aptidão, porque às vezes você fica um pouco martelando naquela posição lá sem ter muita condição e acaba sendo uma obrigação.

De fato, o sujeito 4 apontou características das vivências de lazer, como a liberdade de escolha, a busca por prazer e a não obrigatoriedade. Entretanto, ao praticar esporte em seu momento de trabalho, o atleta não o vivencia em seu tempo disponível, além de possuir uma série de obrigações relacionadas à sua profissão.

Outra razão para justificar a relação entre o esporte e o lazer foi apontada pelo sujeito 7 , o qual afirmou que a relação está no prazer gerado pela prática esportiva e por outras atividades, paralelas a essa prática, que também geram prazer, como a conversa com os amigos.

Esse aspecto foi trabalho por MARCELINO (1999) quando discutiu a relação entre lazer e associativismo para corredores de rua, e aponta que diversos interesses que podem envolver a prática esportiva, inclusive os interesses sociais. No entanto, ao afirmar que a relação entre o esporte e o lazer está no prazer gerado pela prática esportiva, o sujeito 7 coloca todas as situações que geram prazer como vivências de lazer, o que já discutimos ser um equívoco.

Alguns professores afirmaram que o esporte de rendimento é uma possibilidade de lazer para aqueles que o assistem:

O esporte de alto nível, ele não tem absolutamente nada a ver com o lazer pra quem pratica, pra quem assiste é outra história. Você vai lá assistir a um "jogão" de futebol, mas pra quem pratica é um negócio, é uma profissão (Sujeito 1).

Esse aspecto demonstra que o esporte espetáculo também vem possibilitando à concretização de vivências de lazer ligadas a assistência. No entanto, é importante refletir sobre as características de uma sociedade do espetáculo como vem sendo apontada por Debord (2003). De acordo com o autor, o espetáculo constitui o modelo presente da vida socialmente dominante e inclui todas as formas particulares de informação ou propaganda, publicidade ou consumo direto do entretenimento de imagens, mercadorias e eventos culturais, é ainda uma forma de relação social entre pessoas, mediatizada por imagens. Nesse contexto, o esporte espetáculo como lazer vem assumindo contornos ligados a venda de produtos e serviços e por isso, concordamos com Melo e Alves Junior (2003) quando afirmam que é preciso descortinar os princípios que regem o "sistema esportivo" que se mostra aparentemente ingênuo. Aspecto que pode e deve ser debatido nas disciplinas esportivas dos cursos de graduação em Educação Física. 


\section{Abordagem do lazer no âmbito das disciplinas esportivas}

No que se refere à abordagem do lazer em disciplinas esportivas do curso de Educação Física, a maioria dos sujeitos afirmou que a considera importante (seis professores), com exceção dos sujeitos 7 e 8. Alguns sujeitos justificaram que é importante a abordagem do lazer em disciplinas esportivas porque esta é uma das possibilidades das pessoas vivenciarem o esporte.

Além dessa justificativa, o sujeito 6 afirmou que, especialmente na iniciação esportiva, é muito adequado que as atividades sejam ensinadas de forma mais prazerosa. O que novamente denota uma associação do lazer ao prazer e principalmente a realização de atividades que possam levar ao prazer, em uma abordagem denominada de "funcionalista".

O sujeito 2 trouxe uma ideia semelhante, já que a iniciação esportiva, em geral, ocorre na infância, pois afirmou que é importante as disciplinas esportivas abordarem o lazer devido à atuação dos professores de Educação Física com crianças:

Agora, dentro de uma aula de handebol, integrar

elementos de brincadeira, de lazer, de mini-jogo,

eu acho importante, porque, sabe por quê?

Motiva mais as crianças, porque às vezes muito

ensino dos esportes precisa de muita apuração de

técnica, de muitas repetiçóes. Por esse motivo,

quando eu dei aulas para as crianças, eu sempre

comecei uma aula com algo, uma brincadeira,

um jogo de crianças, para motivar, e ativar, 10,

15 minutos. Depois, dependendo do currículo,

a aula de Educação Física mais séria, onde você

ensina uma técnica, assim, e no fim, também

um jogo ou uma brincadeira, uma atividade

recreativa, o equilíbrio, né? Transformar uma

aula de Educação Física em um treinamento se-

ria muito monótono para as crianças e também

não é objetivo [...].

Essa restrição das vivências lúdicas a uma única fase da vida, a infância, é uma idéia que precisa ser analisada com cuidado. Ela reforça a crença de que as pessoas de outras faixas etárias, preocupadas com as coisas "sérias" da vida, não podem se entregar às chamadas "atividades lúdicas", nas quais predomina um suposto caráter inútil-improdutivo (WERNECK, 2004b). Ao contrário desta crença, gostaríamos de despertar nos professores de Educação Física, a partir deste estudo, uma reflexão da importância de oportunizarem experiências lúdicas com o esporte não só para as crianças, mas para pessoas de todas as idades que praticam esportes, especialmente nos espaços de lazer.

Além disso, a prática esportiva no lazer pode contemplar diversas finalidades, como a diversão, o convívio social e a busca de um bom condicionamento físico. Entretanto, o prazer gerado pela prática contribui significativamente para que as pessoas pratiquem esportes com regularidade e mantenham esse hábito por um longo tempo.

O sujeito 2 também considerou importante a abordagem do lazer pelas disciplinas esportivas por outras razões:

eu acho importante também integrar brincadeiras ou exercícios recreativos dentro do treinamento, os atletas gostam. Por exemplo, muitos atletas gostam de hidroginástica, acho uma coisa com música, então já, para recuperar energia, então eu acho que atletas profissionais precisam também de atividades de lazer [...]. Eu sempre estimulo meus atletas, por exemplo, tem teatro, tem um bom filme, então vamos, vamos ver o filme, discutir sobre o filme, ou talvez, quanto tempo você não visita sua família? Então faça-o! [...] acho importante conscientizar o atleta profissional que a vida não é só esporte.

Um primeiro aspecto está relacionado a consciência de que a vida não apresenta apenas a dimensão do trabalho, mas várias dimensões, incluindo o lazer. A segunda, é de que o professor considerou o esporte que os atletas praticam no trabalho semelhante ao esporte que praticam no lazer e, por isso, deveriam buscar outras experiências, além do esporte, como a leitura de livros, o encontro com amigos e outras diferentes possibilidades de vivências.

Quanto ao último entendimento, penso que, de fato, o esporte praticado pelos atletas no trabalho apresenta semelhanças com o esporte praticado no lazer. Contudo, a perspectiva com que esses indivíduos podem se apropriar do esporte nesses diferentes contextos, pode mudar totalmente suas experiências e os sentidos que elas trazem.

O sujeito 1 considera importante a abordagem do lazer nas disciplinas esportivas porque a prática do esporte de lazer precede a do esporte de alto nível: $\mathrm{Na}$ realidade, eu acho que todo mundo, você só é atleta de alto nível é porque, em dado momento, você procurou o esporte como lazer. Não é o contrário, você não sabia que você ia ser atleta de alto nível. Você foi atrás daquela modalidade por conta de um lazer, que alguém te levou, porque você acha legal, porque você viu na televisão, porque você se identificou com o 
ídolo. E aquilo ali é uma forma de lazer. Depois você foi se envolvendo com aquilo, e acabou tendo uma diretriz totalmente inesperada, você tinha aptidão antropométrica para aquela modalidade, você tinha quesitos antropométricos, biológicos e você virou um atleta.

Esta última colocação traz a ideia de uma desvalorização do esporte de lazer, por este ser considerado importante simplesmente porque, a partir dele, surgem os praticantes do esporte de alto rendimento. $\mathrm{O}$ esporte de lazer possui valor em si próprio, como um direito social e uma manifestação cultural que pode apresentar ricas formas e sentidos. Ele pode proporcionar experiências significativas para a vida das pessoas, bem como ser um espaço de reflexão sobre a sociedade. Além disso, a maioria das pessoas pratica esporte no âmbito do lazer, e não são atletas. Mesmo assim, o esporte de lazer tem sido historicamente desvalorizado em relação ao esporte de rendimento por questôes políticas, econômicas e culturais.

Segundo Marcelino (2002) não podemos reforçar a ideia vigente no "senso comum" de que o esporte de lazer pode e deve ser desenvolvida sem os necessários equipamentos, materiais ou profissionais adequados. Tem-se a ideia de que as possibilidades de lazer são necessariamente improvisada e sem qualidade, o que acaba influenciando na ação desenvolvida pelo profissional.

Já o sujeito 5, ao ser questionado sobre a importância da abordagem do lazer pelas disciplinas esportivas, afirmou:

Eu acho que não só como abordagem, mas como

foco mesmo. Eu acho que o lazer é uma área que hoje tem um mercado pra isso [...]. Porque a partir do momento que você ganha dinheiro com isso, você tem que estar muito preparado com o que você vai fazer.

Destacamos na fala a ideia de que o trabalho do professor de Educação Física deve ser feito com responsabilidade, inclusive no âmbito do lazer, que é um espaço de diversão das pessoas. Entretanto, é importante o cuidado para não termos uma visão mercantil do esporte no lazer, como se o trabalho nessa área devesse ser tratado com responsabilidade somente porque gera lucro, e não pela importância dessa dimensão da cultura, principalmente como direito social.

Já os sujeitos 7 e 8, ao contrário dos outros professores, não acham importante que o lazer seja abordado em disciplinas esportivas. O sujeito 7 afirmou que considera importante que as pessoas tenham acesso ao entendimento de lazer, mas que isso não precisa ocorrer necessariamente nas disciplinas esportivas:
Eu acho importante primeiro que as pessoas tenham acesso ao entendimento básico do que é isso, independente se é numa modalidade esportiva. Pra mim, eu não acho que deveria estar ligado à modalidade esportiva, né? Ou seja, eu acho que sim, pode ter uma, é, está incluído entre as possibilidades de desenvolvimento ou de que as pessoas entendam que ali pode ter lazer. Não necessariamente eu tenha que falar com elas que tudo que elas fazem pode ter lazer.

Como o sujeito 7 entende o lazer como "uma oportunidade de experiências prazerosas" que pode estar presente em todas as dimensões da vida, ele não acha necessário que as disciplinas esportivas abordem o lazer, mas acredita que elas são apenas um dos possíveis espaços para tratar do tema. Além disso, ele pensa que os alunos devem adquirir o entendimento de lazer em outras disciplinas, anteriores à disciplina esportiva por ele lecionada, como demonstra na seguinte afirmação:

Bom, se ele já tem o conhecimento prévio de como que isso pode ser feito, porque eu acho que não é futebol que tem que dar conta disso, igual é fisiologia, igual é qualquer outra, cinesiologia, o indivíduo já tem que chegar com esse conteúdo pronto lá, lá ele vai questionar as coisas que acontecem lá e a aplicabilidade daquilo, eu vejo assim [...].

A realização de discussões que abordam somente a questão de que existe o esporte de lazer, bem como outras manifestaçóes esportivas, demonstra que a inserção do lazer nessas disciplinas ainda é superficial. A meu ver, as disciplinas esportivas poderiam também oportunizar a problematização do esporte no lazer e da atuação do profissional de Educação Física neste campo de trabalho.

Entretanto, não se pode desconsiderar que o entendimento de lazer dos professores, bem como as experiências pessoais e profissionais que eles tiveram com o esporte no lazer, influenciarão na forma como problematizarão este tema nas disciplinas que lecionam. Assim, é importante que eles não tenham uma visão restrita de lazer e do esporte de lazer, até porque os alunos tendem a tomar como ponto de referência a opinião de seus professores, mesmo considerando que os alunos não são passivos nesse processo.

Apesar de ter afirmado que não aborda o lazer em sua disciplina, o sujeito 8 disse que discute com os alunos sobre as diferentes formas de manifestação da modalidade esportiva que leciona, dentre elas o lazer, bem como ensina jogos e brincadeiras que podem ser vivenciados em diferentes contextos esportivos, 
inclusive de lazer, dependendo do objetivo do professor de Educação Física e da forma como eles forem realizados.

Em relação ao sujeito 5, apesar de ter dito que considera importante a presença do lazer nas disciplinas esportivas "não só como abordagem, mas como foco mesmo", ele afirmou não abordá-lo.

Ao refletir sobre essa contradição do sujeito 5 , levantamos duas hipóteses: a primeira é de que, nesta questão, ao contrário da questão anterior, ele não considerou o fato de simplesmente discutir a existência do esporte de lazer, dentre outras manifestações do esporte, como uma abordagem do lazer, semelhantemente ao sujeito 8 . Além disso, seria necessário entender o que ele quis dizer com a expressão de ter o lazer como foco nas disciplinas esportivas.

A segunda hipótese é de que ele não aborda o lazer em sua disciplina por não se sentir preparado para isso. Podemos observar indícios desses aspectos em sua afirmação:

Não, não eu não considero não. Considero que a gente discute bastante os meios pra atingir o objetivo. Isso a gente discute bastante com os alunos. Mas eu não tenho linha de aprofundamento pra estar falando o que é lazer. Só acho que a gente tenta sempre mostrar as várias formas da atividade física, ou seja, atividade física e lazer, atividade física e qualidade de vida, atividade física e desempenho [...].

O sujeito 7 também afirmou que não aborda o conteúdo teórico do lazer em sua disciplina, mas que está aberto para discutir com os alunos se eles levantarem essa temática, o que, segundo ele, não ocorre com freqüência. Novamente podemos supor que o sujeito 7 não aborda o lazer porque, além de não considerar que necessariamente as disciplinas esportivas devam abordá-lo, por não se sentir preparado para isso, conforme demonstra na afirmação: Então, eu vejo que a minha contribuição ali não é a discussão teórica sobre o assunto, porque eu não tenho competência nenhuma para discutir nada nesse sentido, mas tenho abertura suficiente para a pessoa, se ela quiser questionar e mostrar que existem outras perspectivas, de discutir essas perspectivas, né?

Apesar dessa falta de conhecimento sobre a temática presente no discurso dos entrevistados alguns afirmam que abordam o lazer em suas disciplinas através da realização de jogos e brincadeiras. E nesse sentido, acreditamos que a realização de jogos e brincadeiras não significa, necessariamente, que o lazer está sendo abordado pelas disciplinas esportivas. De fato, eles fazem parte das manifestaçôes culturais que podem ser vivenciadas no lazer, mas eles também podem ser vivenciados em outros espaços, como o espaço de treinamento, apresentando objetivos bastante diferenciados.

Novamente, a realização de atividades lúdicas foi relacionada com a infância, conforme demonstra a seguinte afirmação do sujeito 4:

Bom, eu acho que eu abordo no sentido das atividades serem lúdicas. Porque quando a gente trabalha, a minha faixa etária é muito voltada pra criança, porque é uma idade boa para aprender ginástica. Então, a gente sempre foca que é importante não só dar o aspecto técnico, mas também trazer o aspecto lúdico, de brincar um pouco nas atividades, do brincar, do fazer, do prazer do brincar em fazer. Então aí essas atividades, então elas vão ser, através das brincadeiras ela acaba aprendendo um pouquinho da ginástica.

Um ponto que destacamos é que alguns professores vêem mais claramente a importância de se abordar o lazer nas disciplinas do curso de licenciatura do que de bacharelado:

Pra mim, um curso de licenciatura tem que ser diferente de um curso de graduação, o bacharelado. A disciplina em si, a forma de abordar os conteúdos, a avaliaçãa, tudo tem que ser diferente [...]. Então, aí eu estou trabalhando até com algumas formas assim, como que a música pode estar ajudando no ensino de voleibol na escola [...]. Isso eu não falo nas turmas do bacharelado, que é a graduação. Por que? Porque aí tem que preparar pra trabalhar com o esporte competitivo, porque esse é o objetivo de quem está fazendo bacharelado (Sujeito 3).

Então, na disciplina esportiva, especialmente aqui na Educação Física, eu vejo essa disciplina muito inserida no bloco da licenciatura, por exemplo, certo? São atividades que o aluno sai daqui e vai para uma escola, e lá ele pode inserir a iniciação daquela disciplina, mas de forma mais lúdica, e de jogos e brincadeiras, dentro daquela faixa de desenvolvimento inicial adequado para essa aprendizagem (Sujeito 6).

Em termos gerais, acredita-se que o licenciado em Educação Física é o profissional qualificado para atuar no âmbito da Educação Física formal - nos segmentos da educação infantil e do ensino nos níveis fundamental, médio e superior -, enquanto o bacharel deve ser qualificado para intervir no campo não escolar - que abrange órgãos públicos, clubes, academias, centros 
comunitários, condomínios, hospitais, dentre outros espaços (IsaYama, 2002). Considerando esta afirmação, o bacharel em Educação Física seria o profissional adequado para atuar em espaços de lazer, logo, ele precisaria de uma formação nessa área, não somente para atuar "com o esporte competitivo".

O sujeito 3 destacou a possibilidade de intervenção de bacharéis em Educação Física nos diversos espaços de lazer, entretanto, afirma que na atual turma de bacharelado em que ele leciona disciplina esportiva, os alunos não demonstraram interesse sobre a discussão do esporte de lazer. E dessa forma, o professor preferiu conduzir a disciplina de acordo com o interesse dos alunos, que é o esporte de rendimento, pensando que deve respeitá-lo.

Alguns argumentos podem ser destacados para discutir o pequeno interesse dos discentes pela discussão do lazer. Um deles está relacionado à inserção limitada que essa temática tem nos currículos dos cursos de Educação Física, conforme destacado por ISAYAMA (2002). Em geral o tema é trabalhado em uma ou duas disciplinas durante o curso e muitas vezes com o caráter técnico e instrumental. Além disso, destacamos novamente a ideia de que lazer é supérfluo e, portanto, deve ser visualizado como

\section{Considerações finais}

Este estudo teve como objetivo diagnosticar e analisar a inserção dos conhecimentos sobre o lazer nos conteúdos desenvolvidos nas disciplinas esportivas do currículo do curso de formação superior em Educação Física da UFMG, a partir do olhar de professores.

Foi demonstrado que a maioria dos docentes entrevistados considera importante a abordagem do lazer nas disciplinas esportivas, entretanto, alguns afirmaram não abordá-lo, enquanto a maioria afirmou que o aborda o tema como conteúdo do curso.

Sobre a forma de abordagem do lazer nas disciplinas esportivas, podemos identificar três maneiras principais: 1) inicialmente o lazer é visualizado como atividade "prática" (jogos e brincadeiras) prazerosa que contribuem para qualificar as ações do esporte de rendimento; 2) O lazer é compreendido como um meio para diminuir e minimizar os problemas resultantes de nossa vida em sociedade (estresse, fadiga, barreiras financeiras, sociais e culturais); 3 ) A associação do lazer as ações ligadas à faixa etária infantil, como se essa esfera só pudesse ser vivenciada por esse grupo social. meio para se atingir outros fins. Por essas razōes destacamos que seria fundamental que o curso de Educação Física ampliasse o olhar dos futuros profissionais de Educação Física sobre as diversas possibilidades de atuação com o esporte não só no âmbito do rendimento.

Apesar das críticas entendemos que a atuação no campo do alto rendimento pode e deve se orientar também por princípios e valores discutidos no âmbito dos estudos do lazer e vice-versa. Sendo assim, destacamos novamente a importância desses conteúdos serem pensados de maneira integrada, principalmente nos cursos de bacharelado em Educação Física, sem desconsiderar as relações estabelecidas entre o lazer e a formação em Licenciatura.

Com relação ao lazer nos cursos de Licenciatura e Bacharelado ainda, ISAYAMA (2002) ressalta que pela falta de compreensão dos professores sobre questōes relativas à formação profissional nessas áreas, pode não ocorrer à diferenciação das disciplinas de um curso para o outro. Por isso, pensamos que esses aspectos ser melhor compreendidos, já que não temos clareza sobre como deve ser desenvolvido o trabalho com lazer em cada um desses campos (Licenciatura e Bacharelado).

Dessa forma, sugerimos maiores reflexōes sobre essas disciplinas, pois pensamos que ainda podem e devem buscar abranger e aprofundar os conhecimentos sobre $o$ esporte de lazer, devido à importância dessa possibilidade de vivenciar o esporte, como foi demonstrado neste estudo, bem como às diversas oportunidades de atuação do profissional de Educação Física neste âmbito.

As disciplinas esportivas são espaços oportunos para a discussão do esporte enquanto direito social, possibilidade lúdica e de experiências ricas e significativas para as pessoas que o vivenciam não só no âmbito do rendimento, mas também do lazer. Por isso, entendemos que essas disciplinas deveriam problematizar a atuação do profissional de Educação Física com o esporte em espaços de lazer, o qual pode incentivar e valorizar a autonomia e criatividade dos indivíduos na prática esportiva, contribuindo na construção de uma sociedade crítica e que participa na construção dessa manifestação cultural.

Uma das maiores dificuldades identificadas pelos sujeitos entrevistados foi à falta de conhecimento e de competências teórico-prática para desenvolver a 
reflexão sobre os conteúdos ligados ao Esporte de Lazer e isso sugere uma ampliação nos espaços de estudos sobre o lazer em cursos de Educação Física. Portanto, também é fundamental que os docentes de disciplinas esportivas busquem conhecimentos sobre o lazer, visto que é um campo de estudos relativamente recente e que provavelmente não esteve presente na formação superior de muitos profissionais formados.
Apesar da existência de um número significativo de estudos referentes a relação entre lazer e esporte, entendemos que estes precisam ser melhor trabalhados nos cursos de formação profissional em Educação Física, tendo em vista a importância e a crescente busca das pessoas pelas vivências esportivas no campo do lazer conforme identificado por STIGGER (2002).

\begin{abstract}
Leisure and sport: the view of sports lectures from the physical education program

The purpose of this study was to diagnose and to analyze the presence of leisure knowledge in sports courses in the physical education program at Federal University of Minas Gerais, Brazil, from the instructors' perspective. In regard to the methodology, the study combined a bibliographical research about Physical Education, sport, leisure and professional formation, with semi-structured interviews with eight lectures from the analyzed program. These professors were selected because they were responsible for sports courses in the second semester of 2007. Data were qualitatively analyzed, and it was identified that most of the lecture (60\%) declared that they approach leisure in their courses, whereas about $40 \%$ declared that they do not. The lecture identified the presence of leisure in sports courses in different ways. Some pointed out that leisure is one of the possibilities to experiment sports; others associated leisure with the idea of games that can be played in classes. Furthermore, leisure was seen as compensation for work; as a way to form athletes, as well as an opportunity for children to play.
\end{abstract}

UNITERMS: Leisure; Sport; Professional formation.

\title{
Referências
}

BETTI, M. Cultura corporal e cultura esportiva. Revista Paulista de Educação Física, São Paulo, v.7, n.2, p.44-51,1993. BRACHT, V. Esporte, Estado, sociedade. Revista Brasileira de Ciências do Esporte, Campinas, v.10, n.2, p.69-73, 1989. DEBORD, G. A sociedade do espetáculo. Disponível em <http://www.geocities.com/projetoperiferia4/se.htm,2003> Acesso em: 23 nov. 2008.

DUMAZEDIER, J. Sociologia empírica do lazer. São Paulo: Perspectiva: SESC, 1979.

GARCIA, G. A relação pedagógica como vínculo libertador: uma experiência de formação docente. In: PATTO, M.H.S. (Org.). Introdução à psicologia escolar. 3.ed. São Paulo: Casa do Psicólogo, 1997.

GUIMARÃES, P.V. Esporte e cultura: a dinâmica do movimento humano nos espaços educativos-culturais das sociedades contemporâneas. In: SILVA, J.E.F.S. Esporte com identidade cultural: coletânea. Brasília: INDESP, 1996.

ISAYAMA, H.F. Recreação e lazer como integrantes de currículos de cursos de graduação em Educação Física. 2002. Tese (Doutorado em Educação Física) - Faculdade de Educação Física, Universidade Estadual de Campinas, Campinas, 2002. . Recreação e lazer na formação profissional em educação física: reflexões sobre o currículo. In: WERNECK, C.L.G.; ISAYAMA, H.F. Lazer, recreação e educação física. Belo Horizonte: Autêntica, 2003.

LINHALES, M.A. A trajetória política do esporte no Brasil: interesses envolvidos, setores excluídos. 1996. Dissertação (Mestrado em Ciências Políticas) - Faculdade de Filosofia e Ciências Humanas, Universidade Federal de Minas Gerais, Belo Horizonte, 1996.

MARCELliNO, N.C. Lazer e educação. Campinas: Papirus, 1987.

. Para tirar os pés do chão: corrida de rua e associativismo. São Paulo: Hucitec, 1999. 
- Apontamentos para a elaboração de um repertório de atividades de recreação e lazer. In: MARCELINO, N.C.

(Org.). Repertório de atividades de recreação e lazer: para hotéis, acampamentos, clubes, prefeituras e outros. Campinas: Papirus, 2002.

MELO, V.A. Esporte, imagem, cinema: diálogos. Rio de Janeiro: Programa Avançado de Cultura Contemporânea, 2004. [Relatório de pesquisa/Pós-Doutorado em Estudos Culturais]. Disponível em: http://www.ceme.eefd.ufrj.br/cinema.

MELO, V.A.; ALVES JUNIOR, E.D. Introdução ao lazer. Barueri: Manole, 2003.

STIGGER, M.P. Esporte, lazer e estilos de vida: um estudo etnográfico. Campinas: Autores Associados, 2002.

TRIVINÓS, A.N.S. Introdução à pesquisa em ciências sociais: a pesquisa qualitativa em educação: o positivismo, a fenomenologia, o marxismo. São Paulo: Atlas, 1992.

VARGAS, A.L. Desporto, fenômeno social. Rio de Janeiro: Sprint, 1995.

VLASTUIN, J.; PILATTI, L.A. Na 'rede' do vôlei de praia: um produto moderno no campo esportivo. Lecturas, Educación Física y Deportes: Revista Digital, Buenos Aires, v.10, n.84, 2005. Disponível em: http://www.efdeportes.com/. Acesso em: 28 nov. 2007.

WERNECK, C.L.G. Lazer: concepções. In: WERNECK, C.L.G. (Org.). Dicionário crítico do lazer. Belo Horizonte: Autêntica, 2004a.

. Lúdico. In: WERNECK, C.L.G. (Org.). Dicionário crítico do lazer. Belo Horizonte: Autêntica, $2004 \mathrm{~b}$.

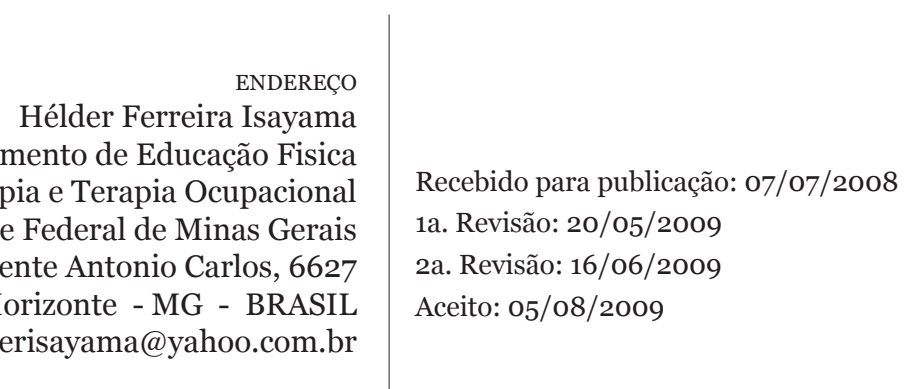

